\title{
Comparative efficacy of mineral trioxide aggregate and biodentine for the repair of pulpal floor perforation
}

\author{
Mirza Md. Arifur Rahman, Mozammal Hossain, Shakila Fatema and Md. Shamsul Alam
}

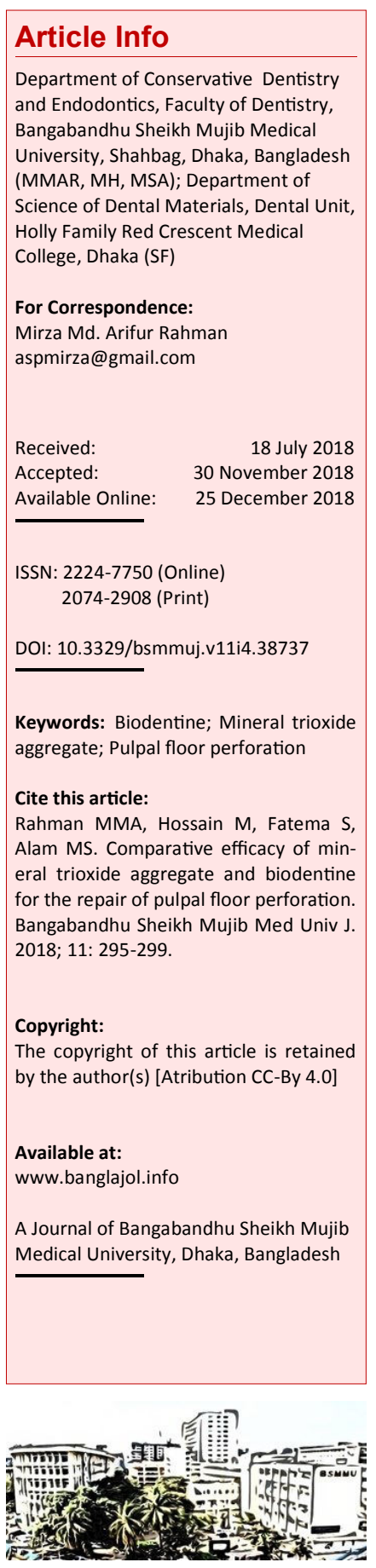

\begin{abstract}
This study compared the clinical outcome of mineral trioxide aggregate and biodentine as repairing materials in the management of pulpal floor perforation in vivo. Among the 30 teeth having pulpal floor perforation, 15 perforations were repaired with mineral trioxide aggregate and the remaining 15 were subjected to biodentine treatment. Following perforation repair, each tooth was then subjected to root canal therapy. Patients were recalled at 3, 6 and 12 months interval. The assessment of pain, tenderness on percussion, and radiological evaluation was performed to determine the reparability of pulpal floor perforation. The results showed that pain, tenderness on percussion and thickness of periodontal ligament were gradually decreased and the perforation site was successfully repaired following mineral trioxide aggregate and biodentine therapy. Furthermore, the overall success rate of biodentine and mineral trioxide aggregate was $98.5 \%$ and $97.2 \%$, respectively, which was not significant. The results indicated that the clinical outcome and repair of pulpal floor perforation by biodentine are almost similar to mineral trioxide aggregate.
\end{abstract}

\section{Introduction}

In the endodontic and restorative treatments, perforation of the roots or the pulp chamber floor is a major complication which results in a chronic inflammatory reaction of the periodontium and formation of granulation tissue as well as irreversible loss of attachment or failure of endodontic treatment. 1 Furthermore, the artificial communication often causes irreversible damage to the periodontium near to the perforation site by the mechanical trauma and engagement of microbially derived substances that certainly accompany the perforation.? Various materials have been proposed for the repair of perforations such as zinc oxideeugenol, amalgam, cavit, gutta-percha, calcium hydroxide, calcium phosphate, composite resin, glass ionomer and resin-modified glass ionomer cement. 3 However, the above materials did not show adequate repair of this iatrogenic damage.

The use of mineral trioxide aggregate has been increased for perforation repair. 4,5 This mineral powder contains hydrophilic particles and contains tricalcium silicate, tricalcium aluminate, tricalcium oxide and other mineral oxides. It has a higher $\mathrm{pH}$ of 12.5 and sets approximately 4 hours in the presence of moisture. 6 Furthermore, it has good sealing ability, favorable biocompatibility, bacteriostatic effect, and the ability to set in the presence of moisture (e.g. blood, tissue fluids). 8 The ability to seal the perforation site by mineral trioxide aggregate is favorable due to its excellent biocompatibility as reported in an in vitro study 7 When comparing to amalgam, zinc oxide eugenol cement, resin-modified cement and intermediate restorative material, it showed better sealing ability. 8-10 The biocompatibility test revealed that it is also capable to repair of the periodontium by the formation of cementum and bone over the material. $7,11,12$ However, it has several disadvantages that include long setting time, less compressive and flexure strength, non-bonding to enamel, dentin and discoloration of teeth and high price. $\frac{7-8}{2}$

Biodentine $^{\mathrm{TM}} \quad$ (Septodont, Saint-Maur-desFossés, France) is a silicate-based material and its use as dentin restorative material and also have endodontic indications similar to those of mineral trioxide aggregate. The main component of the powder is tricalcium silicate, with the addition to the powder of calcium carbonate and zirconium oxide. The liquid is a solution of calcium chloride with a water reducing agent. This material has chemicomechanical bonding with tooth and composite as well as high compressive and flexure strength. $\underline{13}$ Its use as pulp capping agent, root canal obturation, root-end resection, apexification, repair of root perforations, internal resorption and pulpal floor perforations have been expected by in vitro and in vivo studies.13-14 
Therefore, the present study was performed to compare the clinical outcome of mineral trioxide aggregate and biodentine as repairing materials in the management of pulpal floor perforation.

\section{Materials and Methods}

This prospective comparative experimental study was performed from February 2014 to August 2015. Patients with the complaint of iatrogenic pulpal floor perforation attending the outpatient department were selected by lottery method. Clinical and radiological evaluations were performed among 30 participants of which 15 were received pulpal floor perforation with mineral trioxide aggregate and the remaining were treated with biodentine.

\section{Manipulation of materials}

Mineral trioxide aggregate (Angelus, Brazil) powder was mixed with distilled water in a 3:1 powder water ratio until it exhibited putty like consistency according to manufacturer's recommendations. Biodentine $^{\mathrm{TM}}$ (Septodont, Saint-Maur-des-Fossés, France) was supplied a capsule (powder: $0.7 \mathrm{~g}$, liquid: $0.18 \mathrm{~mL}$ ) which was triturated for $30 \mathrm{sec}$ on a mixing device (Cap-mix) at a speed of 4,000-4,200 rotation/min.

\section{Study procedure}

At first, the perforation sites were diagnosed through direct observation of bleeding followed by indirect bleeding assessment by means of a paper point and radiographs. After isolation and cleansing of the perforation site, calcium hydroxide dressing was given for 7 days to minimize bacterial contamination. Root canal re-treatment was initiated (where needed) and after canal preparation calcium hydroxide was used as an intra-canal medicament.

Mineral trioxide aggregate was applied on the perforation site according to previous studies. $\frac{15,16}{1} \mathrm{~A}$ 2-3 $\mathrm{mm}$ height of mineral trioxide aggregate was applied on the perforation site with a carrier gun. Endodontic pluggers followed by a wet cotton pellet were used to condense the material gently into the perforation site. A moistened cotton pellet was placed in the pulp chamber. After 24 hours, the temporary cement was removed to check if mineral trioxide aggregate was set and then tooth was restored with flowable composite resin.

In the case of biodentine, it was packed in the perforations using a plastic filling instrument supplied by the manufacturer. The working time of biodentine is up to $6 \mathrm{~min}$ with a final set at around 10-12 min. Finally, restoration of the tooth was performed with flowable composite resin.

\section{Clinical and radiological evaluations}

The participants were recalled for clinical and radiological evaluation at 3, 6 and 12 months following completion of the treatment. Two evaluators were used to avoid blindness and the clinical and radiological findings were assessed, as follows: a) Pain was determined by visual analog scale system where a $10 \mathrm{~cm}$ long horizontal line with points labeled was used. The pain was calculated as follows: 0: no pain, 1-3: mild pain, 4-6: moderate pain, and 7-10: severe pain; b) The tenderness of tooth on percussion was performed by gentle tapping with the blunt handle of mouth mirror and the participant responses to apical palpation and percussion was calculated according to the following criteria: $0=$ No reaction of pain felt, $1=$ Slight discomfort, 2 = Large discomfort when the patient flinched on examination; c) Recording furcation defects: Class I - The furcation did not have a significant depth, Class II - The furcation cannot be probed completely through to the opposite side, Class III - The furcation can be probed completely through to the opposite side; d) Radiographic assessment: The repair of perforation site was determined by the widening of the periodontal ligament.

\section{Statistical analysis}

Statistical analysis was performed by using computer-based statistical software, SPSS 20.00 version (SPSS Inc. USA). Student's test was used to compare between the results of clinical outcome of mineral trioxide aggregate and biodentine. The $p$ value less than 0.05 was considered as statistically significant.

\section{Results}

The results of clinical outcome at 12 months are shown in the Table I. When the pain was assessed by VAS, it was found that at the end of 12 months, one mineral trioxide aggregate-treated participant reported discomfort but none of the biodentinetreated participant reported. The results of tenderness on palpation showed that 13 biodentineand 14 mineral trioxide aggregate-treated teeth, the participants did not feel any tenderness. One patient of trioxide aggregate treated teeth, participant felt discomfort on percussion, no participants treated by biodentine felt discomfort at 12 months.

Regarding the furcation defect, it was found that furcation defects were gradually healed and finally disappeared at 12 months following completion of the biodentine and mineral trioxide aggregate. When the thickness of periodontal ligament was observed radiographically, it was revealed that thickness gradually decreased following biodentine and mineral trioxide aggregate therapy at 12 months (Figure 1). All biodentine and mineral trioxide aggregate treated teeth had thickness of periodontal ligament less than double. The assess- 


\begin{tabular}{|c|c|c|c|}
\hline \multicolumn{4}{|c|}{ Table I } \\
\hline \multicolumn{4}{|c|}{ Results at 12 months between two groups } \\
\hline & $\begin{array}{c}\text { MTA } \\
(\mathrm{n}=15 \text { teeth })\end{array}$ & $\begin{array}{l}\text { Biodentine } \\
(\mathrm{n}=15 \text { teeth) }\end{array}$ & $\mathrm{p}$ value \\
\hline & No. & No. & \\
\hline \multicolumn{4}{|l|}{ Pain status } \\
\hline No pain & 14 & 15 & 0.309 \\
\hline Mild pain & 1 & 0 & 0.309 \\
\hline Moderate pain & 0 & 0 & 0.309 \\
\hline Severe pain & 0 & 0 & 0.309 \\
\hline \multicolumn{4}{|c|}{ Tenderness on palpation } \\
\hline No pain & 14 & 13 & 0.361 \\
\hline Mild pain & 1 & 2 & 0.361 \\
\hline Moderate pain & 0 & 0 & 0.361 \\
\hline Severe pain & 0 & 0 & 0.361 \\
\hline \multicolumn{4}{|c|}{ Tenderness on percussion } \\
\hline No pain & 14 & 15 & 0.309 \\
\hline Mild pain & 1 & 0 & 0.309 \\
\hline Moderate pain & 0 & 0 & 0.309 \\
\hline Severe pain & 0 & 0 & 0.309 \\
\hline \multicolumn{4}{|l|}{ Furcation defect } \\
\hline Class I & 14 & 15 & 0.309 \\
\hline Class II & 1 & 0 & 0.309 \\
\hline Class III & 0 & 0 & 0.309 \\
\hline
\end{tabular}

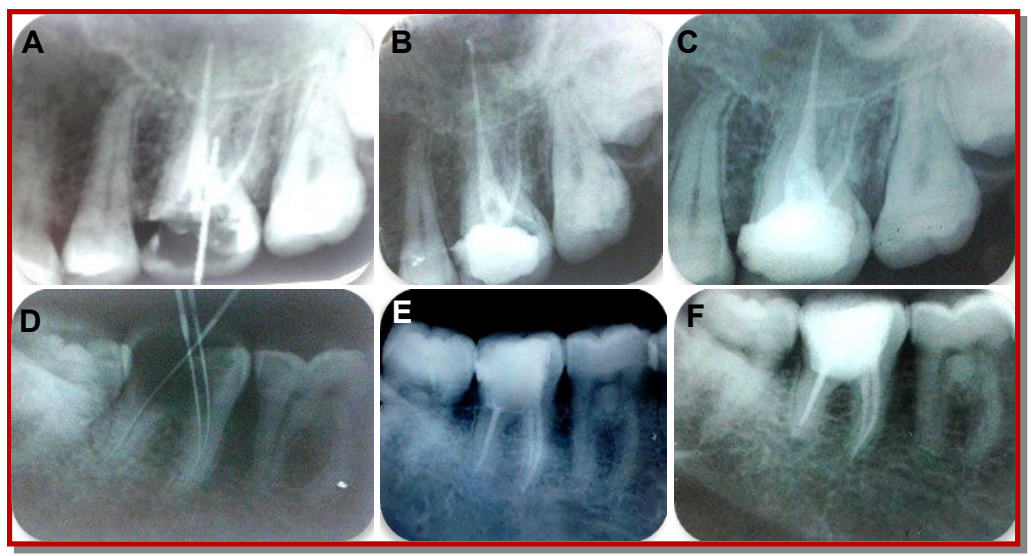

Figure 1: Representative photographs of repair of pulpal floor perforation of maxillary left $1^{\text {st }}$ molar tooth with mineral trioxide aggregate (A: Initial, B: Baseline, C: 12 months) and biodentine (D: Initial, E: Baseline, F: 12 months)

ment of overall success of biodentine and mineral trioxide aggregate was $98.5 \%$ and $97.2 \%$, respectively. The statistical analysis also revealed no differences between the clinical and radiological outcome of biodentine and mineral trioxide aggregate.

\section{Discussion}

The present study revealed that pain and tenderness on percussion, and the thickness of periodontal ligament was gradually decreased with time and the perforation site was successfully repaired by mineral trioxide aggregate and biodentine therapy. Furthermore, the overall success of biodentine and mineral trioxide aggregate was $98.5 \%$ and $97.2 \%$, respectively, and the differences were not significant. A number of studies have indicated that $100 \%$ success rate could be achieved in biodentine and mineral trioxide aggregate treated teeth. $.6,15,16$ Other studies have revealed that biodentine is more capable than the mineral trioxide aggregate in the treatment of perforation repair. 17,18

The reason of reducing pain and tenderness by mineral trioxide aggregate treatment has been reported by some of the previous studies that mineral trioxide aggregate is capable of reducing pain by its high $\mathrm{pH}$, excellent biocompatibility and stimulate mineralization. $\underline{19,20}$ Furthermore, it also initiate formation of cementum and bone ultimately repair and regeneration of periodontal ligament. $\underline{21}$ On the other hand, biodentine may reduce pain and tenderness due to its ability to initiate cementogenesis and osteogenesis. It helps to deposit calcium and phosphate at the furcation area. Furthermore, the higher calcium phosphate ratio may also helps in perforation repair. Other factors such as favorable biocompatibility, osteoconductivity, bioresorption, and biomineralization, calcium carbonate might have beneficial effects on mineralizing. ${ }^{22,} 23$ It has been reported that the release of calcium carbonate and calcium phosphates during the mineralization process is useful in tissue engineering.ㄹ However, some participants felt discomfort at 3 months and it may be due to extrusion of the material (mineral trioxide aggregate and biodentine) into the furcal area. It could happen that biodentine or mineral trioxide aggregate may either directly contact the tissue during extrusion/ overfilling or through its diffusible substances that may leach into periradicular tissues. Furthermore, the destruction and inflammation of periradicular tissues may also responsible for tenderness on percussion. $\underline{.24}$

The results of perforation repair by mineral trioxide aggregate and biodentine were successful. The previous study indicates that biodentine reduces the porosity, and water sorption; the ability to discharge calcium is also responsible for differentiation and hard tissue mineralization. $\underline{25}$ Furthermore, the thickness of periodontal ligament was gradually decreased following both mineral trioxide aggregate and biodentine therapy. The mechanism of periodontal healing is not clarified in this present study. Previous study has indicated that mineral trioxide aggregate allows the growth of cementum (osteocementum) and bone as well as regeneration of periodontal ligament.26 On the other hand, biodentine is competence to reduce microleakage thus diminishing the thickness of periodontal ligament. $\underline{17,18}$ 


\section{Conclusion}

The efficacy of biodentine is similar to mineral trioxide aggregate in the repair of pulpal floor perforation.

\section{Ethical Issue}

The research protocol was approved by the committee and permission for the study was taken from the Institutional Review Board of Bangabandhu Sheikh Mujib Medical University (BSMMU/2014/4871).

\section{Acknowledgement}

This work was supported by the Research Grant for Student, Bangabandhu Sheikh Mujib Medical University.

\section{References}

1. Vanni JR, Della-Bona Á, Figueiredo JA, Pedro G, Voss D, Kopper PM. Radiographic evaluation of furcal perforations sealed with different materials in dog's teeth. J Appl Oral Sci. 2011; 19: 421-25.

2. Pujari MD, Pujar MA, Makandar SD. Endodontics perforations: A review. Ind J Dent Sc. 2012; 4: 13640 .

3. De-Dues G, Petruccelli V, Gurgel-Filho E, Coutinho -Filho T. MTA versus portland cement as repair material for furcal perforations. Int Endod J. 2006; 39: 293-98.

4. Arens DE, Torabinejad M. Repair of furcal perforations with mineral trioxide aggregate: Two case reports. Oral Surg Oral Med Oral Pathol Oral Radiol. 1996; 82: 84-88.

5. Pitt Ford TR, Torabinejad M, McKendry DJ, Hong $\mathrm{CU}$, Kariyawasam SP. Use of mineral trioxide aggregate for repair of furcal perforations. Oral Surg Oral Med Oral Pathol Oral Radiol Endod. 1995; 79: 756-63.

6. Unal GC, Maden M, Isidan. Repair of furcal laterogenic performation with mineral trioxide aggregate: Two year follow-up of two cases. Eur J Dent. 2010; 4: 475-81.

7. Torabinejad M, Hong CU, Pitt Ford TR, Kettering JD. Cytotoxicity of four root end filling materials. J Endod. 1995; 21: 89.

8. Nakata TT, Bae KS, Baumgartner JC. Perforation repair comparing mineral trioxide aggregate and amalgam using an anaerobic bacterial leakage model. J Endod. 1998; 24: 184-86.

9. Lee YC, Yang SF, Hwang YF, Chueh LH, Chung $\mathrm{KH}$. Microleakage of endodontic temporary resto- rative material. J Endod. 1993; 19: 516-20.

10. Katge FA, Shivasharam PR, Patil D. Sealing ability of mineral trioxide aggregate Plus ${ }^{\mathrm{TM}}$ and Biodentine $^{\mathrm{TM}}$ for repair of furcal perforation in primary molars: An in vitro study. Contemp Clin Dent. 2016; 7: 487-92.

11. Shomi KN, Hossain M, Alam MS. Clinical and radiological evaluation of furcal perforation repaired by mineral trioxide aggregate and intermediate restorative material. Bangabandhu Sheikh Mujib Med Univ J. 2017; 10: 70-75.

12. Sultana R, Hossain M, Alam MS. Evaluation of clinical and radiological outcome of mineral trioxide aggregate and calcium hydroxide as indirect pulp capping agents in the treatment of deep carious lesion of permanent teeth. Bangabadhu Sheikh Mujib Med Univ J. 2016; 9: 140-45.

13. Rajasekharan S, Martens LC, Cauwels RG, Verbeeck RM. Biodentine ${ }^{\mathrm{TM}}$ material characteristics and clinical applications: A review of the literature. Eur Arch Paediatr Dent. 2014: 15: 147-58.

14. Strassler HE, Levin R. Biodentine, active biosilicate technology for direct and indirect pulp capping. Oral Health. 2012; 102: 52.

15. Silveria CMM, Sanches-Ayala A, Legravere MO, Pilatti G, Gomes OMM. Repair of furcul perforation with mineral trioxide aggregate: Long-term followup of 2 cases. J Can Dent Assoc. 2008; 74: 729-33.

16. Bora, A, Das, PK, Banerjee, S, Datta, P, Goswami A, Pandey, MB, Zahir S, Kundu GK. Repair of laterogenic perforation with mineral trioxide aggregate: A case report. J Dent Mater Sci. 2015; 14: 73-76.

17. Silva LAB, Pieroni KAMG, Nelson-Filho P, Silva RAB, Hernandéz-Gatón P, Lucisano MP, PaulaSilva FWG, de Queiroz AM. Furcation perforation: Periradicular tissue response to biodentine as a repair material by histopathologic and indirect immunofluorescence analyses. J Endod. 2017; 43: 1137-42.

18. Ramazani N, Sadeghi P. Bacterial leakage of mineral trioxide aggregate, calcium-enriched mixture furcation and biodentine as perforation repair materials in primary molars. Iran Endod J. 2016; 11: 214-18.

19. Tanomaru-Filho M, Tanomaru JM, Barros DB, Watanabe E, Ito IY. In vitro antimicrobial activity of endodontic sealers, MTA-based cements and Portland cement. J Oral Sci. 2007; 49: 41-45.

20. Gomes-Filho JE, Rodrigues G, Watanabe S, Bernabé PF, Lodi CS, Gomes AC, Faria MD, dos Santos AD, Moraes JC . Evaluation of the tissue reaction to fast endodontic cement (CER) and Angelus MTA. J Endod. 2009; 35: 1377-80.

21. Bogen G, Sergio Kuttler S. Mineral trioxide aggre- 
gate obturation: A review and case series. J Endod. 2009; 35: 777-90.

22. Combes C, Miao B, Bareille R, Rey C. Preparation, physical-chemical characterisation and cytocompatibility of calcium carbonate cements. Biomaterials 2006; 27: 1945-54.

23. Dey A, Sommerdijk NA. In situ techniques in biomimetic mineralization studies of calcium carbonate. Chem Soc Rev. 2010; 39: 397-409.

24. Roberts HW, Toth JM, Berzins DW, Charlton DG.
Mineral trioxide aggregate material use in endodontic treatment: A review of the literature. Dent Materials. 2008; 24: 149-64.

25. Clauder T, Shin S. Repair of perforations with MTA: Clinical applications and mechanisms of action. Endod Topics. 2009; 15: 32-55.

26. Altundasar E, Demir B. Management of a perforating internal resorptive defect with mineral trioxide aggregate: A case report. J Endod. 2009; 35: $1441-44$. 